\title{
NATIONAL PREVENTIVE HEALTH RESEARCH STRATEGY
}

$2013-2018$

An integrated model involving researchers and decision makers in creating knowledge 


\section{Context}

The Preventative Health taskforce (2009) called for a National Strategic Framework for preventive health research in Australia: the Healthiest Country by 2020.

The Taskforce saw the need for better research translating evidence into policy and practice.

The Australian National Preventive Health Agency established the Expert Committee on Research in 2011 with the development of a research strategy as its prime task.

The Agency has developed this strategy using an extensive stakeholder consultation process and launched it on 26 June 2013. 


\section{Objectives}

A national effort to:

- promote the necessary approach for knowledge production

- build on current research infrastructure to increase collaboration

- increase research application to policy and practice 


\section{The challenge}

- A new approach required for establishing the evidence for integrated preventive health action

- Historical approaches leave a divide between research and policy and practice

- Use of knowledge translation strategies can meet funding, cultural and capacity barriers 


\section{A new model}

- Current

Knowledge has to be transferred or translated

Relationships are vehicles to relay results

Knowledge to policy in linear

Translation is an end-game
- New

Research transformed into knowledgefor-policy

Relationships are collaborations

Knowledge production is in an integrated cycle in which new knowledge is derived in applications

Use of evidence requires an integrated process of framing the problem, sourcing the evidence, generating the evidence, navigating through shared contexts and applying the evidence 


\section{Building blocks for collaboration and integration}

\section{overcoming the barriers}

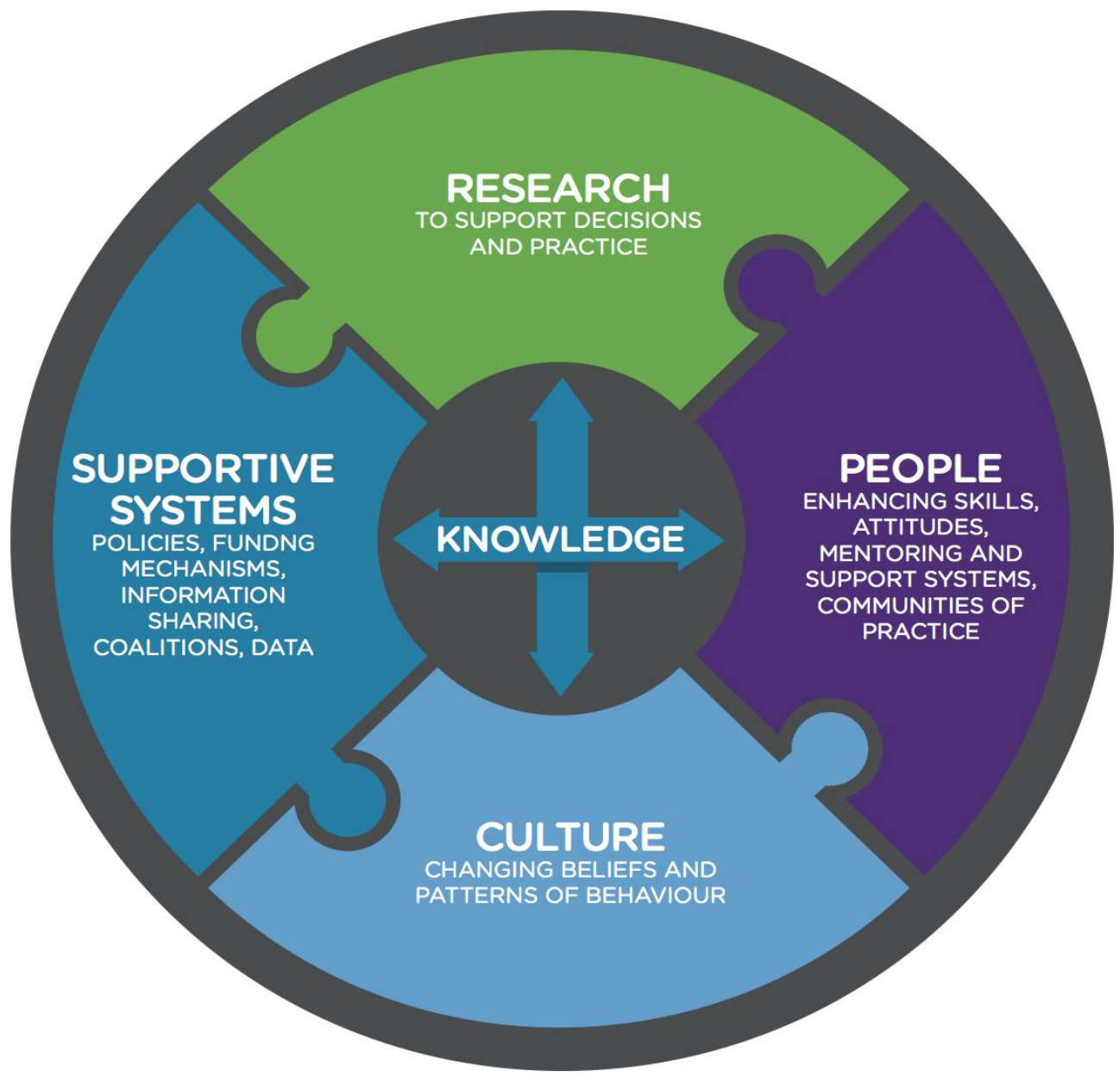




\section{Building block one}

\section{Actions}

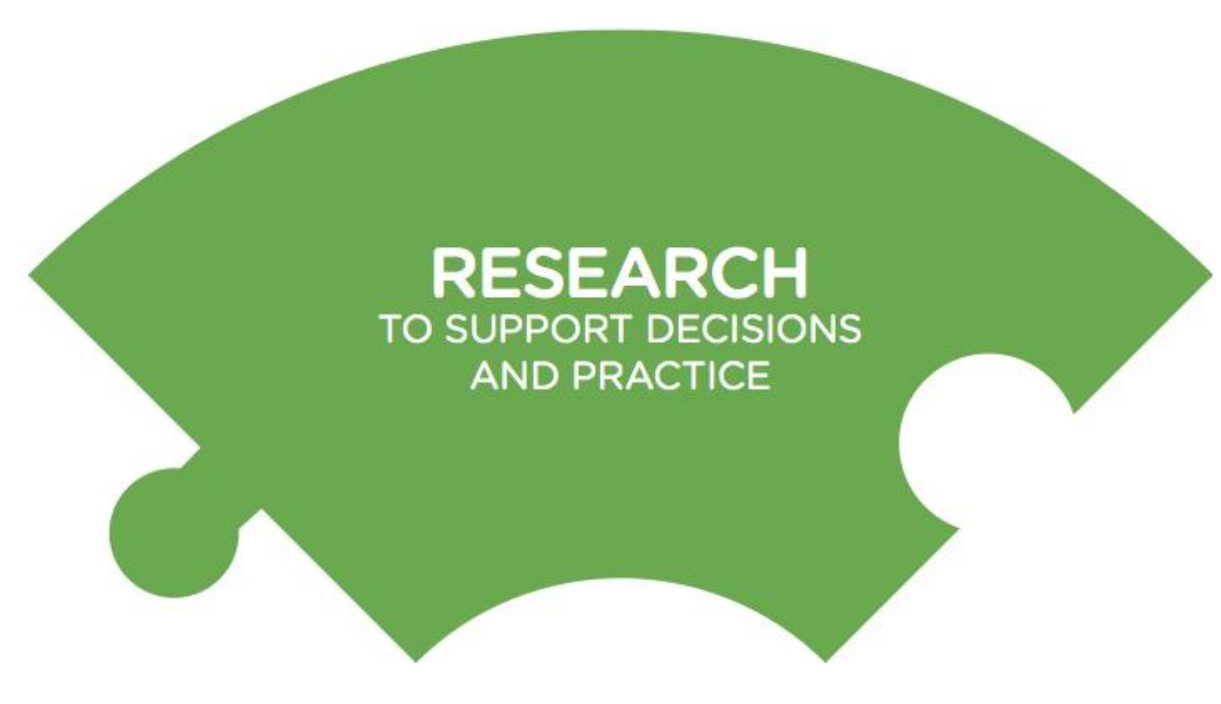

- Bring decision makers and researchers together more often

- Work with non-health partners and mixed disciplines

- Promote methodological research

- Increase partnerships for knowledge production between policy agencies and the research sector

- Promote value of preventive health research to the public 


\section{Building block two}

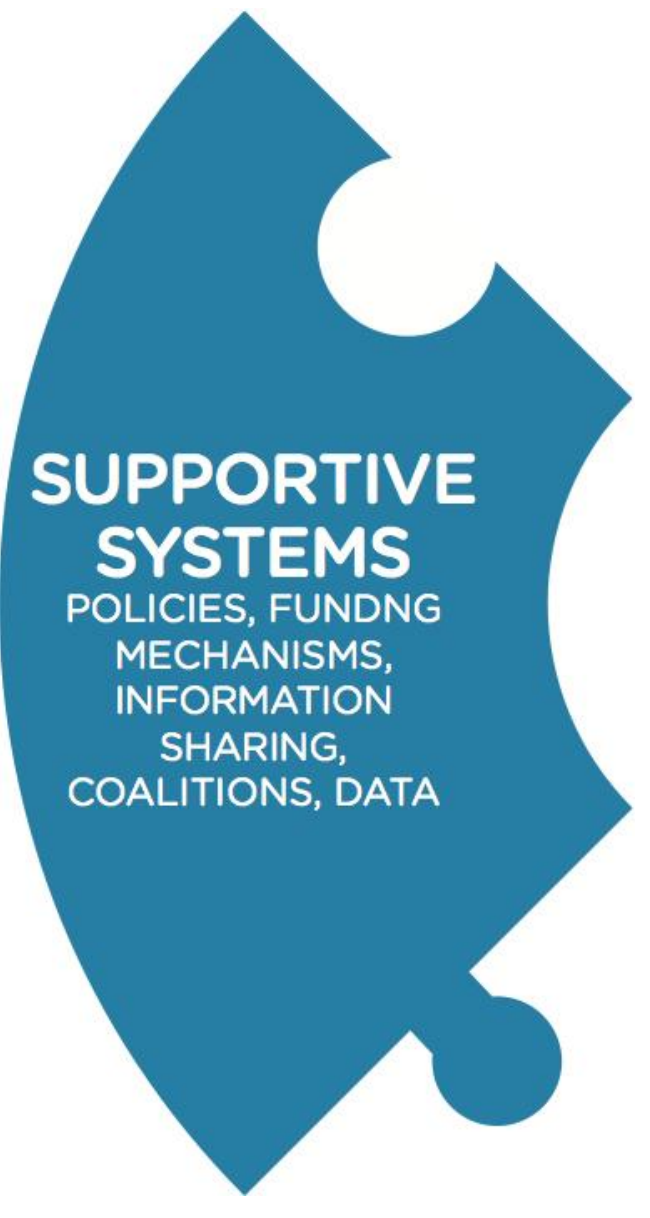

\section{Actions}

- Foster the development of new methods and models for knowledge creation, economic evaluation and research and evaluation syntheses

- Reward exchange of information and relationship building

- Include program evaluations and implementation science in research infrastructure

- Enable publication of knowledge from policy development and program implementation

- Increase access to routinely collected data 


\section{Building block three}

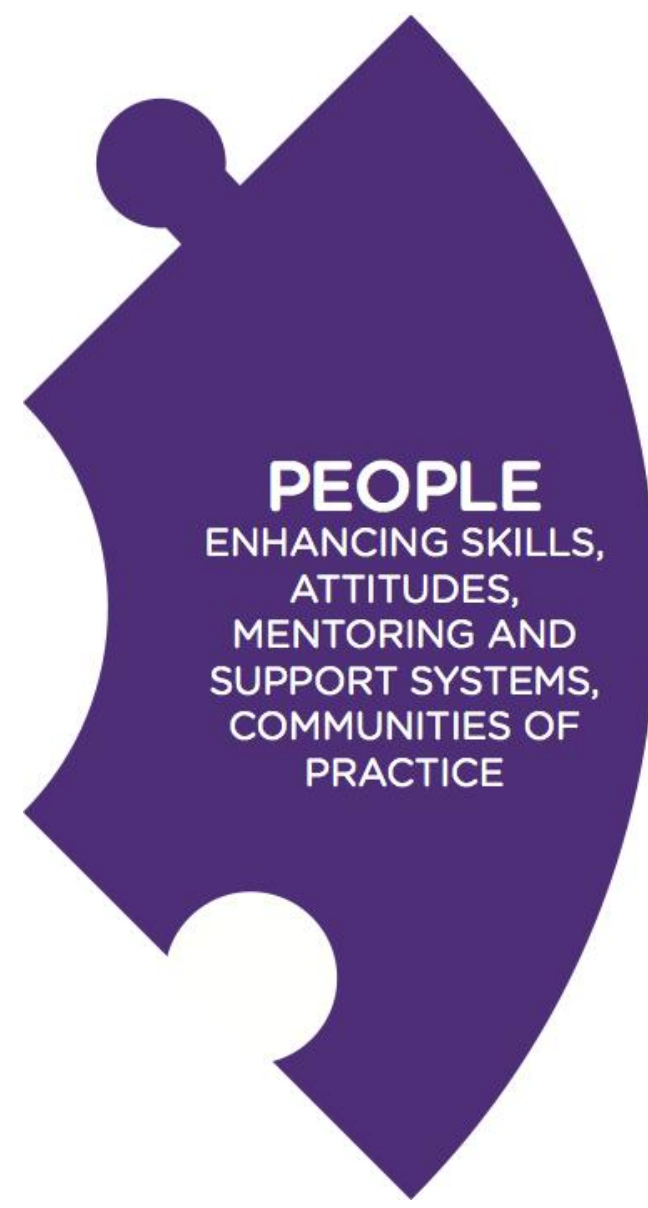

\section{Actions}

- Make careers in preventive health translational research attractive

- Develop a preventive health workforce plan

- Increase dedicated funding for knowledge-for-policy work

- Develop review methods for policy and practice oriented research

- Foster opportunities for partnerships and coalitions

- Develop education programs for decision makers and researchers 


\section{Building block four}

\section{Actions}

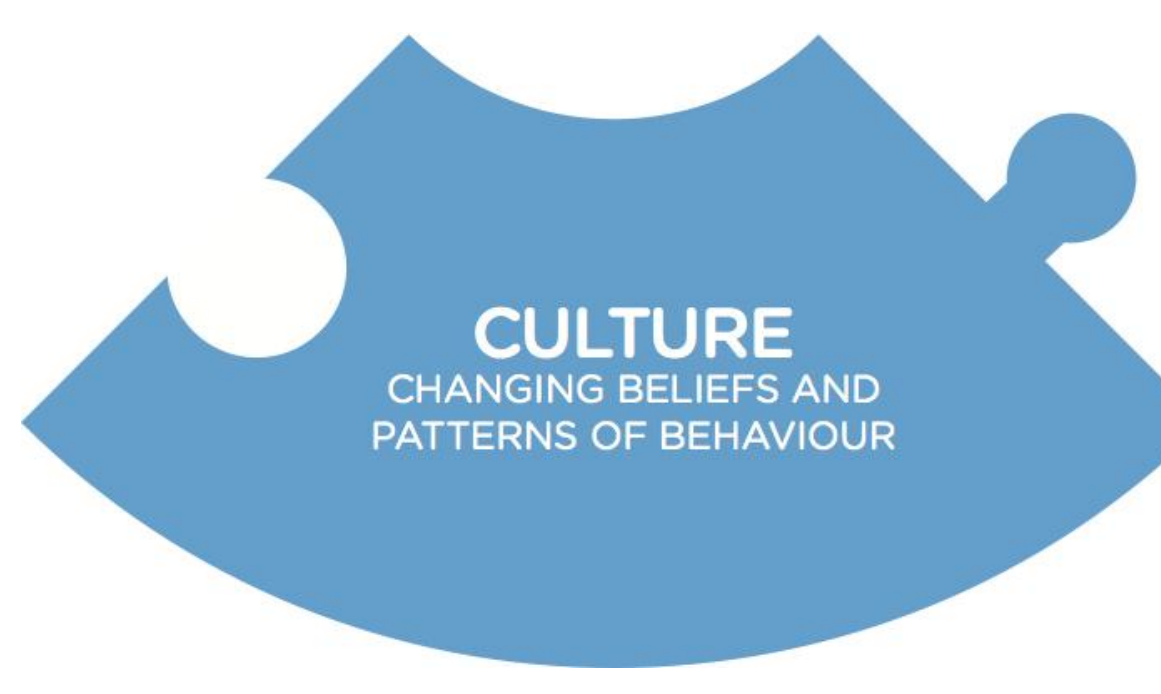

- Promote interest broadly in the collaborative, integrative model

- Develop guidelines for implementing the model

- Develop capacities: decision making based on evidence, formulation of policy questions as research questions

- Develop relationship building skills

- Develop measures of success for this kind of research 


\section{Comments welcome}

First Global Conference on research Integration and Implementation 2013

The complete Research Strategy can be found at: www.anpha.gov.au

Contact: helen.audrey.cameron@anpha.gov.au

\section{promoting \\ a healthy \\ australia}

ANPHA

Australian National Preventive Health Agency Level 1 Canberra House

40 Marcus Clarke Street / GPO BOX 462

Canberra City ACT 2601

P +6126289 2879

E anpha@anpha.gov.au 